\title{
Partially bio-based and tough polyesters, poly(ethylene 2,5-thiophenedicarboxylate-co-1,4-cyclohexanedimethylene 2,5-thiophenedicarboxylate)s
}

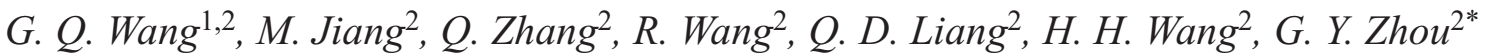 \\ ${ }^{1}$ College of Material Science and Engineering, Jilin Jianzhu University, 130118 Changchun, China \\ ${ }^{2}$ Key Laboratory of Polymer Ecomaterials, Changchun Institute of Applied Chemistry, Chinese Academy of Sciences, \\ Changchun, 130022 Jilin, China
}

Received 18 March 2019; accepted in revised form 1 June 2019

\begin{abstract}
Novel tough bio-based polyesters poly(ethylene 2,5-thiophenedicarboxylate-co-1,4-cyclohexanedimethylene 2,5thiophenedicarboxylate)s (PECTFs) were synthesized from 2,5-thiophenedicarboxylic acid (TDCA), 1,4-cyclohexanedimethanol (CHDM) and ethylene glycol (EG). The microstructure, thermal and mechanical properties were investigated. Poly(ethylene 2,5-thiophenedicarboxylate) (PETF) displayed the glass transition temperature $\left(\sim 64^{\circ} \mathrm{C}\right)$ and tensile strength ( $\sim 72 \mathrm{MPa}$ ) similar to poly(ethylene terephthalate) (PET). However, the nonlinear structure of TDCA resulted in an angle of $148^{\circ}$ between carboxylic acid carbons and the $\mathrm{S}$ atom resulted in a permanent dipole, so the thiophene ring-flipping was hindered and the low elongation at break $(\sim 24 \%)$ was observed for PETF. The peak corresponding to the secondary relaxation shifted to lower temperature due to the incorporation of CHDM, which yielded ductile copolyesters with high elongation at break. When the CHDM content was equal to or higher than $29 \%$, a high elongation at break (>160\%) was observed.
\end{abstract}

Keywords: material testing, mechanical properties, thermal properties

\section{Introduction}

Due to environmental problems and the depletion of oil resources, bio-based materials have attracted more and more people's attention and become a research hot spot [1-5]. Previously, the industrialized biobased polyesters mainly include polylactic acid (PLA), polyhydroxyalkanoates (PHA), polyhydroxybutyrate (PHB), and poly(butylene succinate) (PBS).

Recently, poly(ethylene furanoate) (PEF) derived from 2,5-furandicarboxylic acid (FDCA) becomes the focus of research and development due to the excellent barrier properties and high chemical resistance [6-8]. Hence, PEF is suitable for the preparation of films and 3D printing materials. A reduction in oxygen permeability of $\sim 11 \times$ and carbon dioxide permeability of $19 \times$ at $1 \mathrm{~atm}$ was observed at $35^{\circ} \mathrm{C}$ for PEF compared to poly(ethylene terephthalate) (PET) $[9,10]$. Glass transition temperature of PEF is higher than that of poly(ethylene terephthalate) (PET). However, the melting temperature and crystallization rate are low [11]. The comparison of the hydrolysis of PEF and PET by two cutinases is also researched by Weinberger et al. [12]. Results suggested PEF films were enzymatically hydrolyzed 1.7 times faster than PET films. Compared with the fully amorphous films, PET films with two different crystallinities (10 and 20\%) strongly decreased the enzymatic hydrolyzability. However, the decreasing trend was much more gradual for PEF films.

2,5-Thiophenedicarboxylic acid (TDCA) is another bio-based diacid and can be synthesized by the reaction of adipic acid and thionyl chloride [13].

${ }^{*}$ Corresponding author, e-mail: gyzhou@ciac.ac.cn (C) BME-PT 
Meanwhile, adipic acid can be produced from glucaric or muconic acid [14]. The synthetic routes of 2,5-thiophenedicarboxylic acid (TDCA) from petrochemicals and biomass are summarized in Figure 1 [15]. The structure of TDCA is similar to that of FDCA. The oxygen atom in the furan ring is replaced by the sulfur atom. The angle between carboxylic acid carbons $\left(148^{\circ}\right)$ in the thiophene ring is larger than that $\left(129.4^{\circ}\right)$ in the furan ring. Meanwhile, the resonance energy of the thiophene ring is higher than that of the furan ring and the dipole moment of the thiophene ring is lower than that of the furan ring. As reported from Lotti, poly(propylene 2,5-thiophenedicarboxylate) (PPTF) is indeed more thermally stable than poly(propylene 2,5-furandicarboxylate) (PPF) due to the higher resonance energy of the thiophene ring. Meanwhile, comparied with PPF, $T_{\mathrm{g}}$ of PPTF is lower and the crystallizing ability of PPTF is higher due to the larger angle between carboxylic acid carbons $\left(148^{\circ}\right)$ in the thiophene ring. The permeability behavior of PPTF became better than that of PPF with increasing the relative humidity due to a lower plasticizer effect of water because of the weak polar nature of the thiophene ring. Some TDCA-based polyesters have been synthesized, such as poly(propylene 2,5-thiophenedicarboxylate) (PPTF) [16], poly(butylene 2,5-thiophenedicarboxylate) (PBTF) [17], and poly(butylene adipate/2,5-thiophenedicarboxylate)s (P(BAxBTFy) [18]. At $23^{\circ} \mathrm{C}$, PPTF shows excellent moisture resistance compared to poly(propylene2,5-furandicarboxylate) (PPF). In addition, a reduction in oxygen permeability of $2.0 \times$ and carbon dioxide permeability of $4.75 \times$ was observed at $23^{\circ} \mathrm{C}$ for PBTF compared to PEF.
Ethylene glycol (EG) can be synthesized from bioethanol. 1.4-Cyclohexanedimethanol (CHDM) is a diol with six-member ring. Recently, the use of CHDM as a comonomer of 1,4-butanediol (BDO) is a well-known approach to increase the glass transition temperature of poly(butylene 2,5-furandicarboxylate) (PBF). In addition, CHDM was employed to enhance the toughness and crystallization ability of PEF. However, when the molar percent of CHDM unit was high $(59 \%)$, the copolyester showed the highest elongation at break (186.3\%).

Poly(ethylene 2,5-thiophenedicarboxylate) (PETF) has been synthesized by other researchers. However, the tensile properties are not characterized. In this paper, the tensile properties are characterized for PETF for the first time. However, PETF with high tensile strength exhibits the low elongation at break. In order to solve the problem, poly(ethylene 2,5-thiophenedicarboxylate-co-1,4-cyclohexanedimethylene 2,5-thiophenedicarboxylate)s (PECTFs) and poly(1,4cyclohexanedimethylene 2,5-thiophenedicarboxylate) (PCTF) were synthesized by incorporating 1,4cyclohexanedimethanol (CHDM). The effects of CHDM on sequence structure, crystallization behaviors, thermal properties, and mechanical properties were investigated.

\section{Experimental section}

\subsection{Materials}

2,5-Thiophenedicarboxylic acid (TDCA, 99\%) was purchased from Heowns Biochem Technologies Limited Liability Company (China). 1,4-Cyclohexanedimethanol (CHDM) (99\%) with $67 \mathrm{~mol} \%$

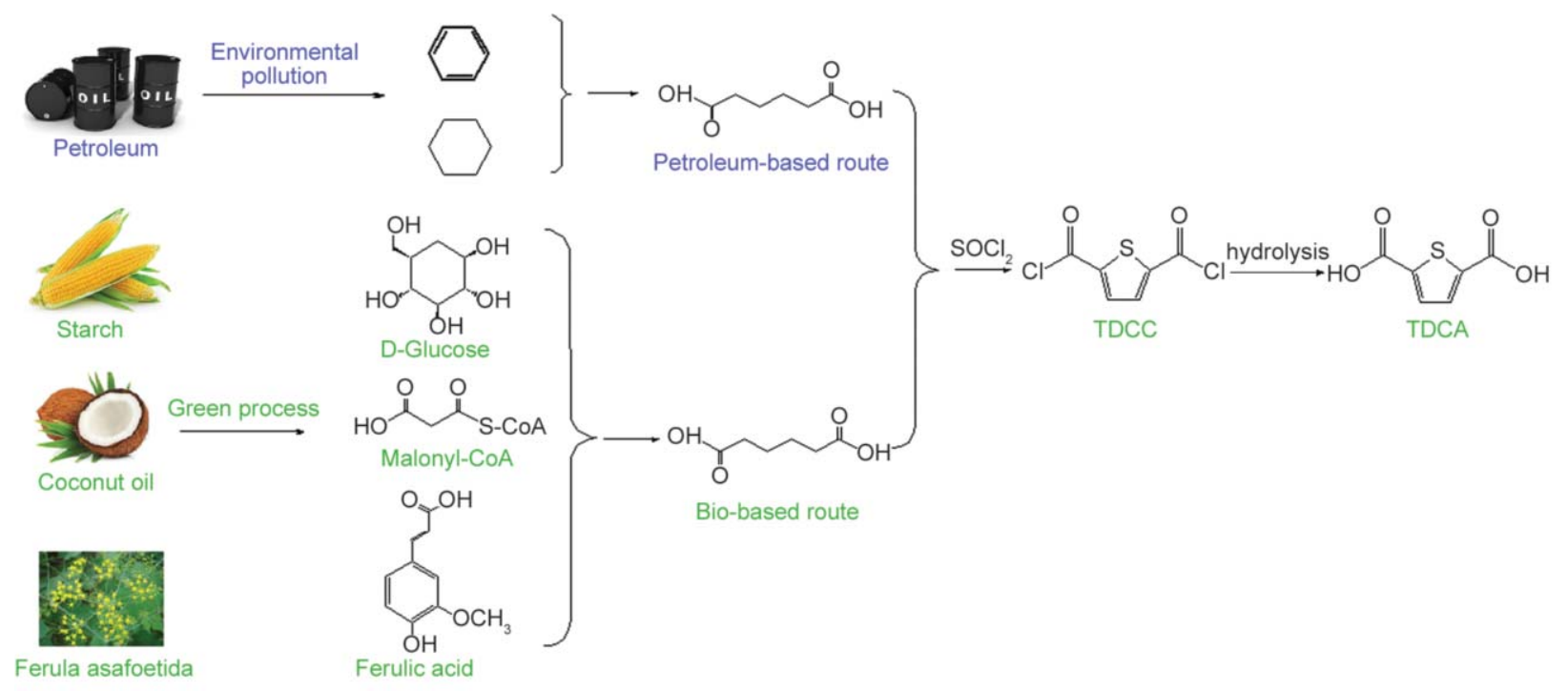

Figure 1. The synthetic routes of 2,5-thiophenedicarboxylic acid (TDCA) from petrochemicals and biomass. 
trans-isomer was purchased from Aladdin Reagent Co. Ltd (Shanghai, China). Ethylene glycol (EG, 99\%) were purchased from Sinopharm Chemical Reagent limited corporation (China). Tetrabutyltitanate (TBT, 99\%) were purchased from Tianjin Guangfu Fine Chemical Research (China).

\subsection{Synthesis of PETF, PCTF and PECTs}

Poly(ethylene 2,5-thiophenedicarboxylate) (PETF), poly(1,4-cyclohexanedimethylene 2,5-thiophenedicarboxylate) (PCTF) and poly(ethylene-co-1,4-cyclohexanedimethylene 2,5-thiophenedicarboxylate)s (PECTFs) were synthesised, using a standard two steps polycondensation process. TBT $(30 \mu \mathrm{l} / 0.1 \mathrm{~mol}$ TDCA), TDCA (0.2 mol), and diols (EG and/or $\mathrm{CHDM})(\mathrm{diol} / \mathrm{TDCA}=1.6$ molar ratio) were introduced into the reactor with $\mathrm{N}_{2}$ inlet. The reactor was heated to $230^{\circ} \mathrm{C}$ and stirred for $2 \mathrm{~h}$. A vacuum $(50 \mathrm{~Pa})$ was applied gradually to the polycondensation system after $0.5 \mathrm{~h}$. The reactor was heated to $250^{\circ} \mathrm{C}$ The reaction was stopped when the rod-climbing phenomenon occurred. Finally, the reaction pressure was returned to the normal atmospheric pressure by the introduction of $\mathrm{N}_{2}$ and the product was cooled to room temperature by air naturally. All samples were brown and transparent. Finally, the samples were dried under vacuum at $60^{\circ} \mathrm{C}$ for $24 \mathrm{~h}$ and sealed. PECTF29, PECTF49, PECTF77 denoted 29, 49 and $77 \mathrm{~mol} \%$ 1,4-cyclohexanedimethylene 2,5-thiophenedicarboxylate unit $(\mathrm{CT})$ in the copolyesters determined by ${ }^{1} \mathrm{H}$ NMR.

\subsection{Analysis}

Weight-average molecular weight $\left(M_{\mathrm{w}}\right)$ and molecular weight distribution $(D)$ were determined by GPC using a Waters 1515 HPLC apparatus (USA). Hexafluoroisopropanol (HFIP) containing $5 \mathrm{mmol} / 1$ sodium trifluoroacetate $\left(\mathrm{CF}_{3} \mathrm{COONa}\right)$ was used as the solvent at $30^{\circ} \mathrm{C}$ and the solvent flow rate was $1.0 \mathrm{ml} / \mathrm{min} . M_{\mathrm{w}}$ and $D$ were determined using polymethyl methacrylate (PMMA) standards with a narrow $D$.

${ }^{1} \mathrm{H}$ NMR spectra were recorded with a Bruker spectrometer (Germany, $600 \mathrm{MHz}$ ) in $\mathrm{CF}_{3} \mathrm{COOD}$. Tetramethylsilane (TMS) was used as the internal standard. ${ }^{13} \mathrm{C}$ NMR spectra were recorded using the same NMR spectrometer $(150 \mathrm{MHz})$. The molar percentage of 1,4-cyclohexanedimethylene 2,5-thiophenedicarboxylate $(\mathrm{CT})$ unit in copolymers $\left(\Phi_{\mathrm{CT}}\right)$, numberaverage sequence length of $\mathrm{CT}$ unit $\left(L_{\mathrm{n}, \mathrm{CT}}\right)$, number-average sequence length of ethylene 2,5thiophenedicarboxylate (ET) unit $\left(L_{\mathrm{n}, \mathrm{ET}}\right)$ and the degree of randomness $(R)$ were calculated.

The thermal transitions and non-isothermal crystallization behavior were recorded by differential scanning calorimeter (DSC) (Switzerland Mettler Toledo DSC 1 differential scanning calorimeter, MettlerToledo International Inc., Zurich, Switzerland). The samples were placed in alumina crucibles. Nitrogen gas flow rate was $50 \mathrm{ml} / \mathrm{min}$. First, PETF, PCTF and PECTFs were cooled to $-30^{\circ} \mathrm{C}$ and then heated to $290^{\circ} \mathrm{C}$ at a rate of $10^{\circ} \mathrm{C} / \mathrm{min}$, the temperature was hold for $3 \mathrm{~min}$, and cooled again to $-30^{\circ} \mathrm{C}$ at a rate of $10^{\circ} \mathrm{C} / \mathrm{min}$. Finally, PETF, PCTF and PECTFs were heated again to $290^{\circ} \mathrm{C}$ at a rate of $10^{\circ} \mathrm{C} / \mathrm{min}$. Melting temperature $\left(T_{\mathrm{m}}\right)$, melting enthalpy $\left(\Delta H_{\mathrm{m}}\right)$, cold crystallization temperature $\left(T_{\mathrm{cc}}\right)$ and its enthalpy $\left(\Delta H_{\mathrm{cc}}\right)$ were obtained on the $1^{\text {st }}$ heating scan at $10^{\circ} \mathrm{C} / \mathrm{min}$. The glass transition temperature $\left(T_{\mathrm{g}}\right)$ was taken as the midpoint of the step transition observed on the $2^{\text {nd }}$ heating scan at $10^{\circ} \mathrm{C} / \mathrm{min}$.

Thermogravimetric analysis (TGA) was performed on a Mettler TGA/DSC 1 instrument. The samples $(5 \mathrm{mg}$ ) were placed in ceramic crucibles. Nitrogen gas flow rate was $50 \mathrm{ml} / \mathrm{min}$. The samples were heated from 30 to $600^{\circ} \mathrm{C}$ at a rate of $10^{\circ} \mathrm{C} / \mathrm{min}$. The degradation temperature at $5 \%$ weight loss $\left(T_{\mathrm{d}, 5 \%}\right)$ and the residue weight at $600{ }^{\circ} \mathrm{C}\left(W_{600}\right)$ were obtained.

The tensile properties of PETF, PCTF and PECTFs were measured with Instron-1121 tester according to ASTM D638. The crosshead speed was $5 \mathrm{~mm} / \mathrm{min}$. The specimens were prepared by injection molding. The dimension of middle segment was $3.20 \mathrm{~mm}$ thickness $\times 3.18 \mathrm{~mm}$ width. Five samples were tested.

Dynamic thermomechanical analysis (DMA) of PETF, PCTF and PECTFs was carried out using a Dynamical Mechanical thermal Analyzer DMA+450 (Metravib) in tensile mode. The samples $(50 \mathrm{~mm}$ length $\times 5 \mathrm{~mm}$ width $\times 1.5 \mathrm{~mm}$ thickness) were prepared by injection molding method. A dynamic displacement of $20 \mu \mathrm{m}$ was applied at frequencies of $10 \mathrm{~Hz}$. The specimens were run from -130 to $40^{\circ} \mathrm{C}$ in at a rate of $2{ }^{\circ} \mathrm{C} / \mathrm{min}$.

\section{Results and discussion}

\subsection{Synthesis and structures}

PETF, PCTF, and PECTFs were synthesized from EG, CHDM and TDCA. Figure 2 shows GPC traces of PETF, PCTF and PECTFs. The weight-average molecular weights $\left(M_{\mathrm{w}}\right)$ of all polyesters prepared 


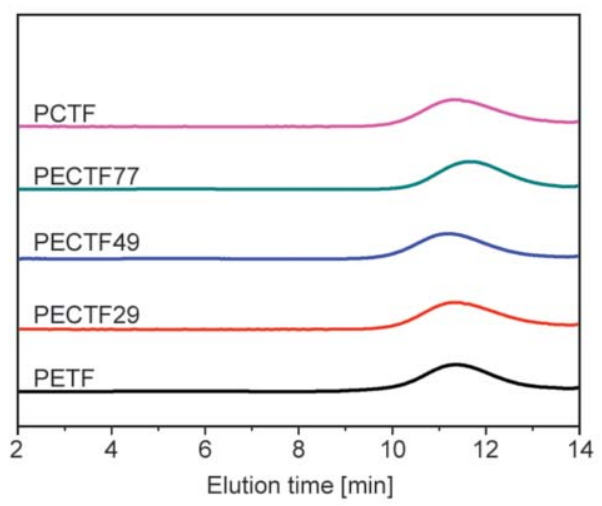

Figure 2. GPC traces of PETF, PCTF and PECTFs.

were higher than $10000 \mathrm{~g} \cdot \mathrm{mol}^{-1}$, and the molecular weight distribution $(D)$ was 1.9-3.3 (Table 1 ). We don't find a shoulder at higher molecular weight from GPC chromatograms. PETF, PCTF, and PECTFs were synthesized by bulk polymerization method.
The viscosity of the system was high at the reaction temperature, which made it difficult to react evenly. Hence, high $D$ values were observed. PET and PEF also exhibit similar high $D$ (2.58 and 2.63) [19]. Because CHDM is more rigid than EG, the viscosity of PCTF is higher than that of PETF. Meanwhile, the boiling point of CHDM is higher than that of EG, so CHDM is difficult to remove during the polymerization and the polymerization rate is slower. Based on the above two reasons, the molecular weight of PCTF is the lowest. Figure 3 shows the synthetic route of PECTFs. Figure 4 shows chemical structures of ETE, ETC, and CTC unites in PECTFs.

Figure 5 shows ${ }^{1} \mathrm{H}$ NMR spectra of PETF, PCTF, and PECTFs. For PETF, the peaks at $4.63 \mathrm{ppm}$ (a) and $7.72 \mathrm{ppm}(\mathbf{b})$ were assigned to the $\mathrm{CH}_{2}$ in EG unit and $\mathrm{CH}$ in the thiophene ring, respectively. For PCTF,<smiles>O=C(O)c1ccc(C(=O)O)s1</smiles><smiles>CCCCCCCCCOC(=O)c1ccc(C(=O)OCCOCCOC(=O)c2ccc(C(=O)OCC3CCC(CO)CC3)s2)s1</smiles>

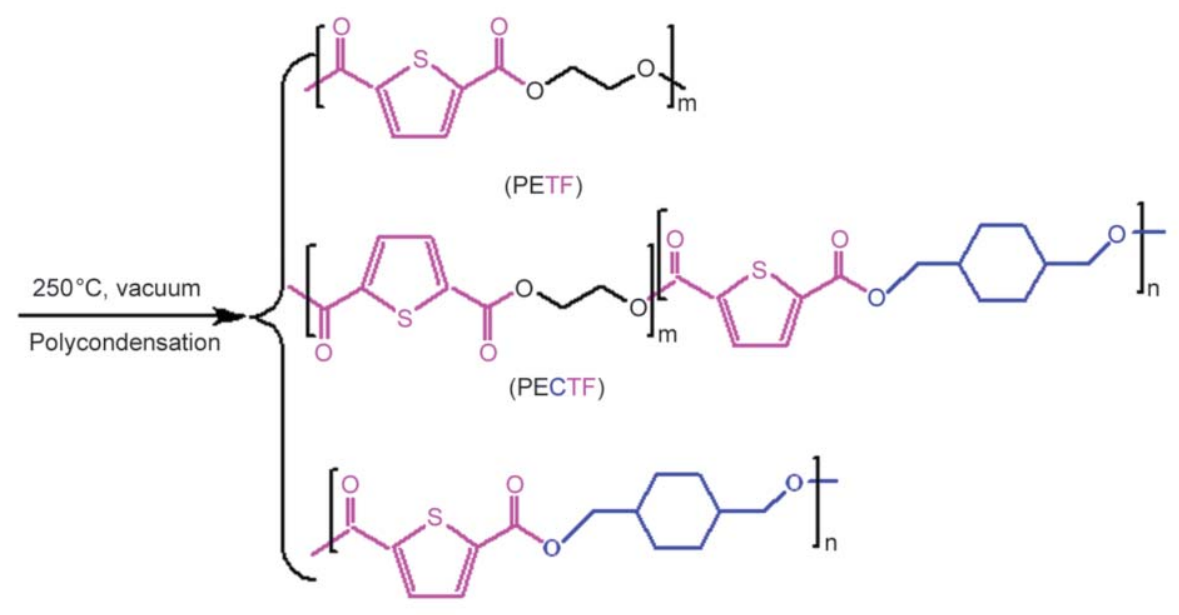

(PCTF)

Figure 3. The synthetic route of PETF, PCTF and PECTFs. 
Table 1. Microstructures and molecular weights of PETF, PCTF, and PECTFs.

\begin{tabular}{|c|c|c|c|c|c|c|c|c|c|c|}
\hline \multirow[t]{2}{*}{ Sample } & \multicolumn{2}{|c|}{$\begin{array}{c}\Phi_{\mathrm{CT}} \\
{[\mathrm{mol} \%]}\end{array}$} & \multicolumn{2}{|c|}{$\begin{array}{c}\Phi_{\text {trans }} \\
{[\mathrm{mol} \%]}\end{array}$} & \multirow[t]{2}{*}{$L_{\mathrm{n}, \mathrm{CT}}$} & \multirow[t]{2}{*}{$L_{\mathrm{n}, \mathrm{ET}}$} & \multirow[t]{2}{*}{$R$} & \multirow{2}{*}{$\begin{array}{c}M_{\mathrm{w}} \\
{[\mathrm{g} / \mathrm{mol}]}\end{array}$} & \multirow[t]{2}{*}{$D$} & \multirow{2}{*}{$\begin{array}{l}\text { Yield } \\
{[\%]}\end{array}$} \\
\hline & in feed & in copolymers & in feed & in copolymers & & & & & & \\
\hline PETF & 0 & 0 & - & - & - & - & - & 36700 & 3.3 & 85 \\
\hline PECTF29 & 20.0 & 29.0 & $33: 67$ & $30: 70$ & 1.52 & 3.25 & 0.97 & 32300 & 1.9 & 86 \\
\hline PECTF49 & 37.5 & 49.0 & $33: 67$ & $31: 69$ & 1.98 & 2.05 & 0.99 & 40700 & 3.2 & 88 \\
\hline PECTF77 & 60.0 & 77.0 & $33: 67$ & $32: 68$ & 4.68 & 1.35 & 0.95 & 20500 & 2.7 & 88 \\
\hline PCTF & 100.0 & 100.0 & $33: 67$ & $35: 65$ & - & - & - & 11000 & 2.3 & 89 \\
\hline
\end{tabular}

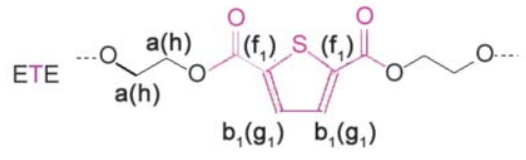

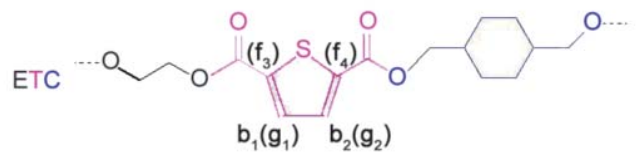

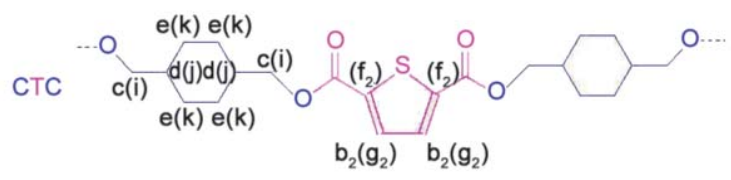

Figure 4. Chemical structures of ETE, ETC, and CTC unites in PECTFs.

the peak at $7.69 \mathrm{ppm}\left(\mathbf{c}_{2}\right)$ was assigned to the $\mathrm{CH}$ in the thiophene ring. The peaks at $4.25\left(\mathbf{d}_{\text {cis }}\right)$ and $4.12 \mathrm{ppm}$ ( $\left.\mathbf{d}_{\text {trans }}\right)$ were assigned to cis- and transmethylene protons of oxymethylene in CHDM unit. The peaks at $1.96\left(\mathbf{d}_{\text {cis }}\right)$ and $1.69 \mathrm{ppm}\left(\mathbf{d}_{\text {trans }}\right)$ were assigned to cis- and trans-methylene protons of the cyclohexane ring in CHDM unit. The peaks $\left(\mathbf{e}_{\text {cis }}\right)$ at 1.58 and $1.46 \mathrm{ppm}$ were assigned to cis-methane protons of the cyclohexane ring in CHDM unit. The peaks ( $\left.\mathbf{e}_{\text {trans }}\right)$ at 1.83 and 1.05 ppm were assigned to

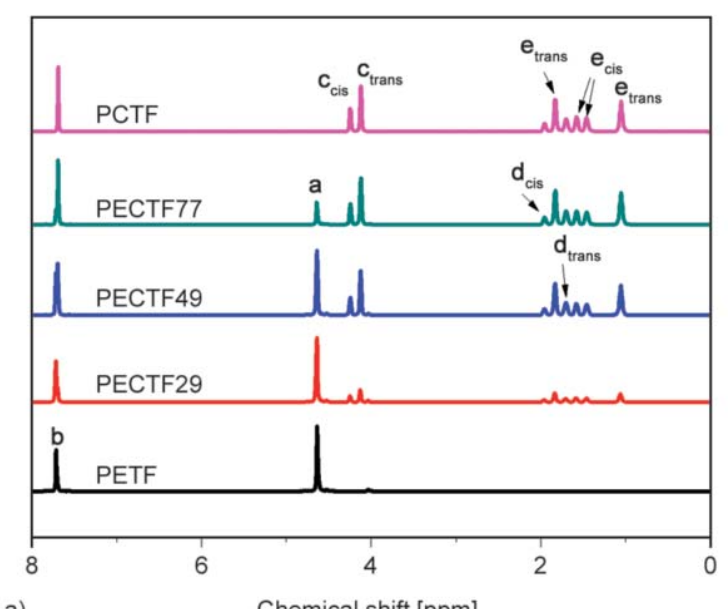

a)

Chemical shift [ppm] trans-methane protons of the cyclohexane ring in CHDM unit.

To determine the sequence distribution, PETF, PCTF, and PECTFs were characterized by quantitative ${ }^{13} \mathrm{C}$ NMR spectra. For PETF, the peak $\left(\mathbf{f}_{\mathbf{1}}\right)$ at 130.4 ppm was assigned to the nonprotonated aromatic carbon atoms. For PCTF, the peak $\left(\mathbf{f}_{\mathbf{2}}\right)$ at 130.8 ppm was assigned to the nonprotonated aromatic carbon atoms. However, for PECTFs, the resonance of the nonprotonated aromatic carbon atoms (f) has split into four peaks $\left(\mathbf{f}_{\mathbf{1}}, \mathbf{f}_{\mathbf{2}}, \mathbf{f}_{\mathbf{3}}\right.$, and $\left.\mathbf{f}_{\mathbf{4}}\right)$ correspond to four types of carbon atoms (Figure 4 and Figure 6). $\Phi_{\mathrm{CT}}, L_{\mathrm{n}, \mathrm{CT}}, L_{\mathrm{n}, \mathrm{ET}}, R$ and $\Phi_{\text {trans }}$ are estimated according to Equation (1)-(5), respectively:

$\Phi_{\mathrm{CT}}[\mathrm{mol} \%]=\frac{I_{\mathrm{c}}}{I_{\mathrm{a}}+I_{\mathrm{c}}} \cdot 100$

$L_{\mathrm{n}, \mathrm{CT}}=1+\frac{2 I_{\mathrm{f}_{2}}}{I_{\mathrm{f}_{3}}+I_{\mathrm{f}_{4}}}$

$L_{\mathrm{n}, \mathrm{ET}}=1+\frac{2 I_{\mathrm{f}_{1}}}{I_{\mathrm{f}_{3}}+I_{\mathrm{f}_{4}}}$

$R=\frac{1}{L_{\mathrm{n}, \mathrm{CT}}}+\frac{1}{L_{\mathrm{n}, \mathrm{ET}}}$

Figure 5. ${ }^{1} \mathrm{H}$ NMR spectra of PETF, PCTF, and PECTFs, a) the whole spectra, b) magnification of chemical shift $\mathbf{b}$. 
$\Phi_{\text {trans }}[\mathrm{mol} \%]=\frac{I_{\mathrm{c}, \text { trans }}}{I_{\mathrm{c}, \mathrm{cis}}+I_{\mathrm{c}, \text { trans }}} \cdot 100$

where $\Phi_{\mathrm{CT}}$ represents the molar percentage of CT in the copolyesters. $I_{\mathrm{a}}$ and $I_{\mathrm{c}}$ represent the integrals of the corresponding peaks a and $\mathbf{c}$, respectively. $L_{\mathrm{n}, \mathrm{CT}}$ and $L_{\mathrm{n}, \mathrm{ET}}$ represent the number-average sequence length of CT and ET units, respectively. $R$ represents the degree of randomness. $\Phi_{\text {trans }}$ represents the moleratio of trans-isomer in copolyesters.

With increasing the CHDM content, the number-average sequence length of CT unit $\left(L_{n, \mathrm{CT}}\right)$ gradually increased and the number-average sequence length of ET unit $\left(L_{\mathrm{n}, \mathrm{ET}}\right)$ gradually decreased. The $R$ values of all PECTFs were between 0.95 and 1.01, indicating that all PECTFs were random copolyesters. Because the boiling point of $\mathrm{CHDM}\left(286^{\circ} \mathrm{C}\right)$ was much higher than that of EG $\left(197^{\circ} \mathrm{C}\right)$ and $\mathrm{EG}$ was more likely to evaporate and remove during the reaction, the CHDM content in copolymers was higher than that in feed. The mole ratio of trans-isomer in copolyesters was basically equal to that in feed, indicating there was basically no the configuration transformation between cis and trans isomers at high temperatures in this study.

\subsection{Thermal properties}

Figure 7 shows DSC curves of PETF, PCTF, and PECTFs. For all polyesters, glass transition temperatures $\left(T_{\mathrm{g}}\right)$ were between 64 and $69^{\circ} \mathrm{C}$. For PECTF29, PECTF49, and PECTF77, melt crystallization temperatures $\left(T_{\mathrm{c}}\right)$ were not observed in the cooling curve and melting temperatures $\left(T_{\mathrm{m}}\right)$ were not observed in the first and second heating curves, indicating they were amorphous copolyesters. However, for PETF, a cold crystallization peak $\left(\Delta H_{\mathrm{cc}}=13.5 \mathrm{~J} / \mathrm{g}\right)$ and a melting peak $\left(\Delta H_{\mathrm{m}}=16.4 \mathrm{~J} / \mathrm{g}\right)$ were observed at 154.0 and $190.4^{\circ} \mathrm{C}$ in the first heating curve, respectively. It was clear that PETF could crystallize slowly. Surprisingly, poly(1,4-cyclohexylenedimethylene terephthalate) (PCT) and poly(1,4-cyclohexanedimethylene furanoate) (PCF) are crystalline polymers with

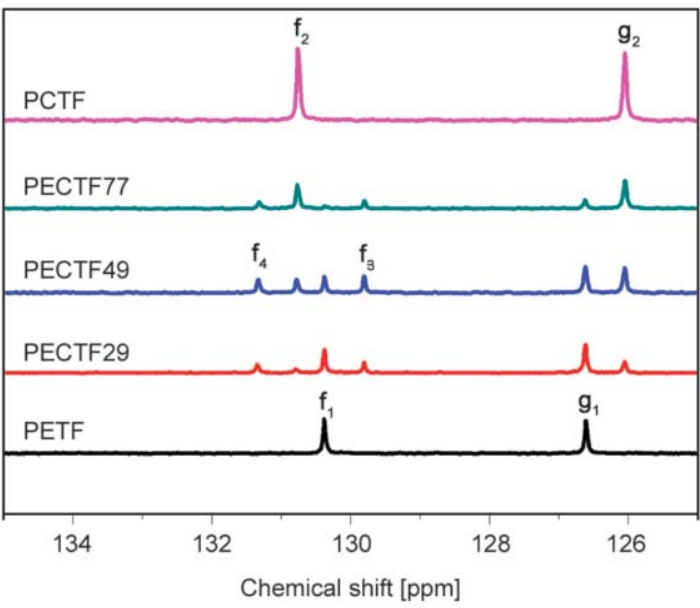

b)

Figure 6. ${ }^{13} \mathrm{C}$ NMR spectra of PETF, PCTF, and PECTFs, a) the whole spectra, b) magnification of chemical shifts $\mathbf{f}$ and $\mathbf{g}$.
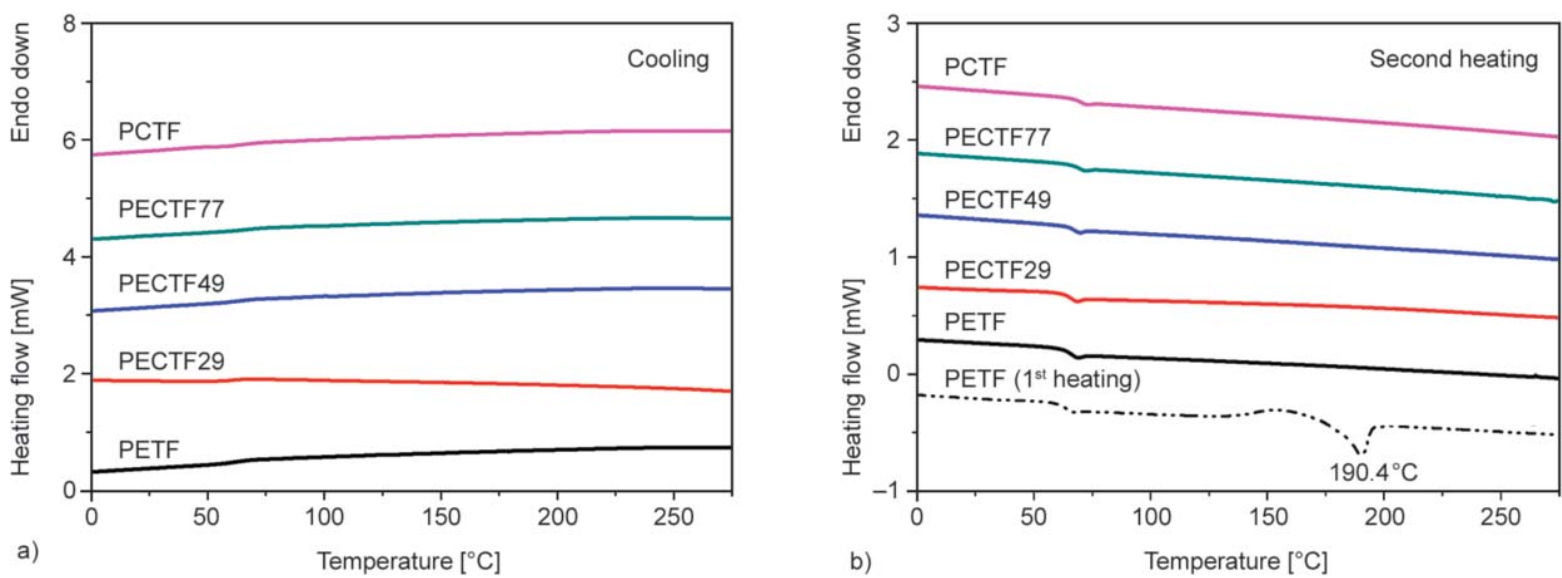

Figure 7. DSC curves of PETF, PCTF, and PECTFs, a) cooling, b) second heating. 

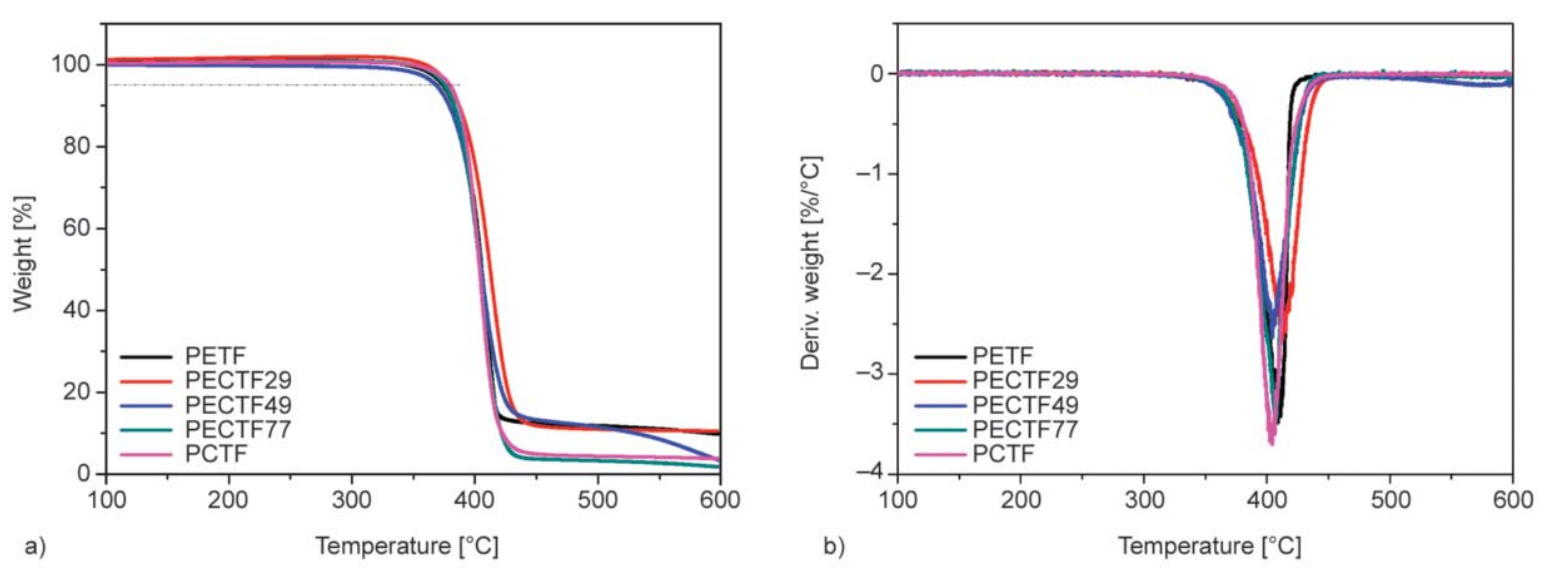

Figure 8. TGA (a) and DTG (b) curves of PETF, PCTF, and PECTFs under dynamic $\mathrm{N}_{2}$ atmosphere.

Table 2. Thermal properties of PETF, PCTF, and PECTFs obtained by DSC and TGA.

\begin{tabular}{|c|c|c|c|c|c|c|c|c|}
\hline \multirow[b]{2}{*}{ Sample } & \multicolumn{4}{|c|}{$1^{\text {st }}$ heating } & \multirow{2}{*}{$\begin{array}{c}2^{\text {nd }} \text { heating } \\
T_{\mathrm{g}} \\
{\left[{ }^{\circ} \mathrm{C}\right]}\end{array}$} & \multirow[b]{2}{*}{$\begin{array}{l}T_{\mathrm{d}, 5 \%} \% \\
{\left[{ }^{\circ} \mathrm{C}\right]}\end{array}$} & \multirow[b]{2}{*}{$\begin{array}{c}T_{\mathrm{d}, \max } \\
{\left[{ }^{\circ} \mathbf{C}\right]}\end{array}$} & \multirow[b]{2}{*}{$\begin{array}{l}W_{600} \\
{[\%]}\end{array}$} \\
\hline & $\begin{array}{c}\boldsymbol{T}_{\mathrm{m}} \\
{\left[{ }^{\circ} \mathbf{C}\right]}\end{array}$ & $\begin{array}{l}\Delta H_{\mathrm{m}} \\
{[\mathbf{J} / \mathrm{g}]}\end{array}$ & $\begin{array}{c}T_{\text {cc }} \\
{\left[{ }^{\circ} \mathbf{C}\right]}\end{array}$ & $\begin{array}{l}\Delta \boldsymbol{H}_{\mathrm{cc}} \\
{[\mathrm{J} / \mathrm{g}]}\end{array}$ & & & & \\
\hline PETF & 190.4 & 16.4 & 154.0 & 13.5 & 64.1 & 374.4 & 409.1 & 9.9 \\
\hline PECTF29 & - & - & - & - & 64.3 & 378.3 & 412.8 & 10.5 \\
\hline PECTF49 & - & - & - & - & 65.4 & 368.7 & 406.5 & 3.4 \\
\hline PECTF77 & - & - & - & - & 67.7 & 375.6 & 407.5 & 1.8 \\
\hline PCTF & - & - & - & - & 68.7 & 379.7 & 404.3 & 3.9 \\
\hline
\end{tabular}

fast crystallization rate [20,21], but PCTF is a amorphous polymer. Therefore, CHDM is more suitable for toughening PETF without considering the effect of crystallinity.

Figure 8 shows TGA and DTG curves of PETF, PCTF, and PECTFs under dynamic $\mathrm{N}_{2}$ atmosphere. The temperature at $5 \%$ weight loss $\left(T_{\mathrm{d}, 5 \%}\right)$, the temperature at the maximum decomposition rate $\left(T_{\mathrm{d}, \max }\right)$ and the residue weight at $600{ }^{\circ} \mathrm{C}\left(W_{600}\right)$ are summarized in Table 2. For all samples, $T_{\mathrm{d}, 5 \%}$ and $T_{\mathrm{d} \text {,max }}$ were all higher than 360 and $400^{\circ} \mathrm{C}$, respectively. It meant that all samples exhibited excellent thermal stabilities.

\subsection{Tensile properties and dynamic mechanical behavior}

Tensile tests were carried out at $25^{\circ} \mathrm{C}$ at a constant stretching rate of $5 \mathrm{~mm} / \mathrm{min}$ to determine the mechanical properties of PETF, PCTF, and PECTFs. Young's modulus, tensile strength, elongation at break, injection temperatures are summarized in Table 3. Figure 9 shows the characteristic tensile behavior of PETF, PCTF, and PECTFs. Figure 10 shows the $\beta$ relaxation from DMA of PETF, PCTF, and PECTFs and the $\beta$ relaxation temperatures are given in Table 3.

For PETF, the highest tensile strength $(\sim 72 \mathrm{MPa})$ was observed. However, the nonlinear structure of TDCA

Table 3. Young's modulus, tensile strength and elongation at break of PETF, PCTF, and PECTFs.

\begin{tabular}{|l|c|c|c|c|c|}
\hline \multicolumn{1}{|c|}{ Sample } & $\begin{array}{c}\boldsymbol{E} \\
{[\mathbf{M P a}]}\end{array}$ & $\begin{array}{c}\boldsymbol{\sigma}_{\mathbf{m}} \\
{[\mathbf{M P a}]}\end{array}$ & $\begin{array}{c}\boldsymbol{\varepsilon}_{\mathbf{b}} \\
{[\mathbf{\%}]}\end{array}$ & $\begin{array}{c}\text { Injection temperature } \\
{\left[{ }^{\circ} \mathbf{C}\right]}\end{array}$ & Reference \\
\hline PETF & $1760 \pm 120$ & $71.7 \pm 0.6$ & $23.9 \pm 10.1$ & 210 & This work \\
\hline PECTF29 & $1500 \pm 150$ & $62.2 \pm 3.2$ & $208 \pm 22$ & 230 & This work \\
\hline PECTF49 & $1640 \pm 10$ & $57.0 \pm 0.5$ & $256 \pm 43$ & 230 & This work \\
\hline PECTF77 & $1560 \pm 20$ & $50.6 \pm 0.4$ & $169 \pm 5$ & 230 & This work \\
\hline PCTF & $1350 \pm 210$ & $49.0 \pm 0.3$ & $176 \pm 23$ & - & This work \\
\hline PEF & $2800 \pm 120$ & $85 \pm 9$ & $5 \pm 1$ & - & {$[23]$} \\
\hline PECF-59 & $1740 \pm 150$ & $59 \pm 4$ & $186 \pm 14$ & - & {$[23]$} \\
\hline PCF & $2100 \pm 200$ & $62 \pm 4$ & $18 \pm 4$ & - & {$[24]$} \\
\hline PET & 2297 & 65 & 173 & & {[} \\
\hline
\end{tabular}




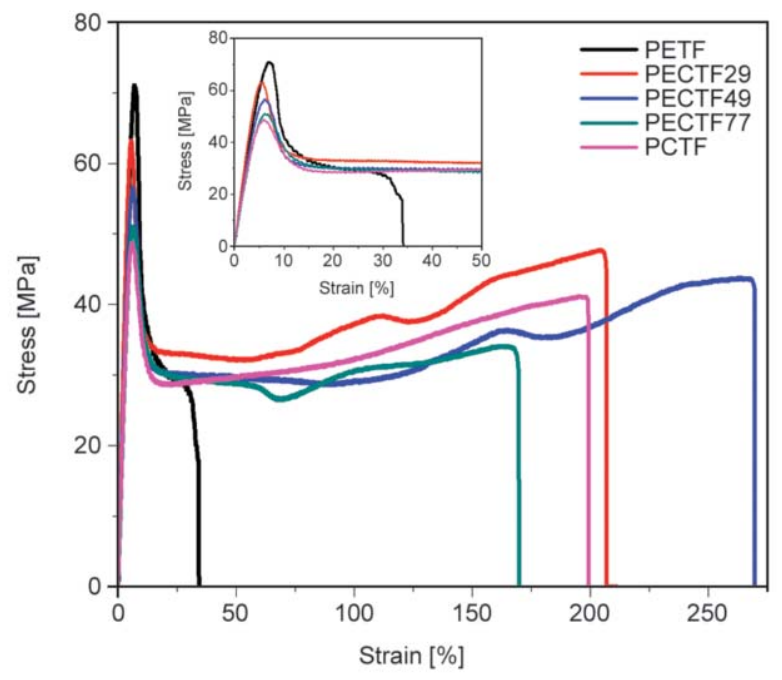

Figure 9. Stress-strain curves of PETF, PCTF, and PECTFs.

resulted in an angle of $148^{\circ}$ between carboxylic acid carbons. Moreover, the $\mathrm{S}$ atom resulted in the permanent dipole. Considering the above-mentioned reasons, the thiophene ring-flipping was hindered and the low elongation at break ( $24 \%$ ) was observed for PETF. The similar phenomenon was reported for poly (ethylene furanoate) (PEF) with the similar structure [11]. Compared with PEF, PETF exhibited the lower tensile strength and the higher elongation at break, which should be attributed to the larger angle between carboxylic acid carbons $\left(148^{\circ}\right)$ and the weaker intermolecular forces caused by the $\mathrm{S}$ atom. However, compared with PETF, PET exhibited the lower tensile strength and the higher elongation at break, which should be attributed to an angle of $180^{\circ}$ between carboxylic acid carbons and the benzene ringflipping. Comparison of PETF, PEF and PET was summarized in Table 4.

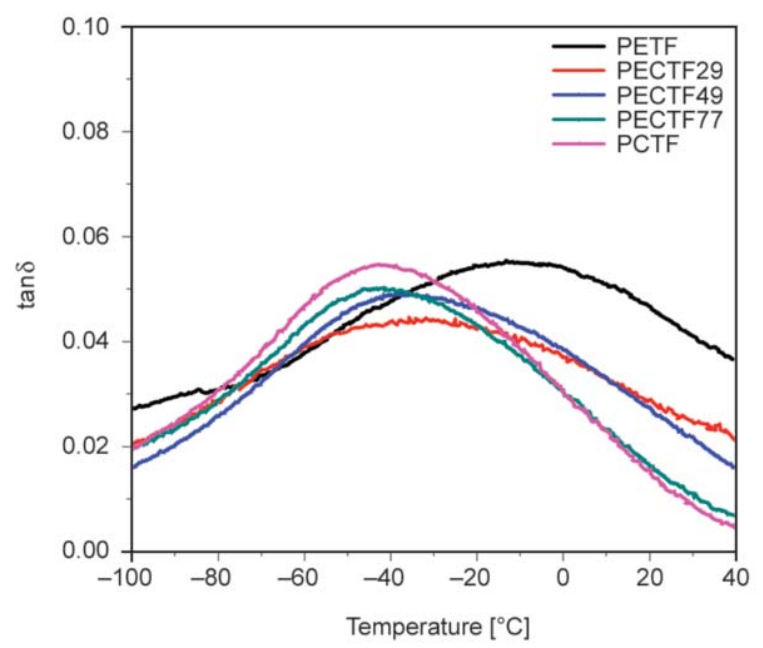

Figure 10. The $\beta$ relaxation from DMA of PETF, PCTF, and PECTFs.
Table 4. Comparison of PETF, PEF and PET [11, 25, 26].

\begin{tabular}{|l|c|c|c|}
\hline \multicolumn{1}{|c|}{ Polyesters } & PETF & PEF \\
\hline $\begin{array}{l}\text { An angle between car- } \\
\left.\text { boxylic acid carbons [ }{ }^{\circ}\right]\end{array}$ & 148 & 129.4 & 180 \\
\hline Ring & Polar & Polar & Nonpolar \\
\hline Hindered ring-flipping? & Yes & Yes & No \\
\hline Heteroatom? & S & O & No \\
\hline The permanent dipole? & Yes & Yes & No \\
\hline
\end{tabular}

For PECTF29, PECTF49, PECTF77, and PCTF, they were ductile materials (elongation at break: 169256\%). PETF and PECTF49 with similar molecular weights and molecular weight distributions can be compared. Obviously, the difference in mechanical properties is not caused by the difference in molecular weights. The reason might be that the more unites and extensive cooperative motion occurred induced by the conformational transition of cyclohexylene ring. As shown in Figure 10 and Table 5, with the increase of CHDM content, the $\beta$ relaxation temperature shifted to the lower temperature, indicating that it was easier to give rise to the secondary relaxation due to the incorporation of CHDM. For another polyester poly(1,4-cyclohexylenedimethylene 1,4-cyclohexylenedicarboxylate) (PCC), the conformation transition of cyclohexylene ring was described as follows by Liu and Yee [22]: 'The cyclohexylene ring has two most stable conformations (chair conformations). The chair-twist boat-chair conformation transition is possible in polyesters. The angle between 1,4-cyclohexylene and its neighbors changes from 180 to $114^{\circ}$, which induces the connected segments to translate and/or rotate. Meanwhile, the mobility of chain enhances, which leads to slide between polymer chains and shear yield.' Compared with poly $(1,4-$ cyclohexanedimethylene 2,5-furandicarboxylate) (PCF) with fast crystallization rate, PCTF exhibited the lower tensile strength and the higher elongation at break due to the weaker intermolecular forces

Table 5. The $\beta$ relaxation peaks of PETF, PCTF, and PECTFs determined by DMA.

\begin{tabular}{|l|c|}
\hline Samples & $\begin{array}{c}\boldsymbol{\beta} \text { relaxation peaks } \\
{\left[{ }^{\circ} \mathbf{C}\right]}\end{array}$ \\
\hline PETF & -18 \\
\hline PECTF29 & -34 \\
\hline PECTF49 & -46 \\
\hline PECTF77 & -51 \\
\hline PCTF & -52 \\
\hline
\end{tabular}


caused by the $\mathrm{S}$ atom, the larger angle between carboxylic acid carbons $\left(148^{\circ}\right)$ and the amorphous characteristic. Compared with poly(ethylene-co-1,4-cyclohexanedimethylene 2,5-furandicarboxylate)s (PECFs) with the high content of CHDM (59\%), PECTF29 exhibited better mechanical properties and higher bio-based content.

\section{Conclusions}

Bio-based polyesters poly(ethylene 2,5-thiophenedicarboxylate-co-1,4-cyclohexanedimethylene 2,5-thiophenedicarboxylate)s were synthesized using melt polycondensation method. Weight-average molecular weights of PETF, PCTF, and PECTFs are higher than $10000 \mathrm{~g} / \mathrm{mol}$. For all polyesters, glass transition temperatures $\left(T_{\mathrm{g}}\right)$ were between 64 and $69^{\circ} \mathrm{C}$. PETF is a semi-crystalline polymer with slow crystallization rate. However, other copolyesters synthesized are amorphous polymers. For PETF, the highest tensile strength $(\sim 72 \mathrm{MPa})$ and low elongation at break $(\sim 24 \%)$ were observed. When the CHDM content was higher than or equal to $29 \%$, high elongation at break $(>160 \%)$ was observed because the $\beta$ relaxation peak shifted to the lower temperature. Additionally, compared with PEF, PETF exhibited the lower tensile strength and the higher elongation at break due to the larger angle between carboxylic acid carbons $\left(148^{\circ}\right)$ and the weaker intermolecular forces caused by the $\mathrm{S}$ atom. Compared with poly $(1,4-$ cyclohexanedimethylene 2,5-furandicarboxylate) with fast crystallization rate, PCTF exhibited the lower tensile strength and the higher elongation at break due to the weaker intermolecular forces caused by the $\mathrm{S}$ atom, the larger angle between carboxylic acid carbons $\left(148^{\circ}\right)$ and the amorphous characteristic.

\section{Acknowledgements}

This research was supported by the National Nature Science Foundation of China (51803211) and Key R\&D Program of Guangdong Province (No. 2018B09096001).

\section{References}

[1] Muñoz-Guerra S., Lavilla C., Japu C., de Ilarduya A. M.: Renewable terephthalate polyesters from carbohydratebased bicyclic monomers. Green Chemistry, 16, 17161739 (2014).

https://doi.org/10.1039/C3GC42394H
[2] Gandini A., Lacerda T. M., Carvalho A. J. F., Trovatti E.: Progress of polymers from renewable resources: $\mathrm{Fu}-$ rans, vegetable oils, and polysaccharides. Chemical Reviews, 116, 1637-1669 (2016).

https://doi.org/10.1021/acs.chemrev.5b00264

[3] Gandini A., Lacerda T. M.: From monomers to polymers from renewable resources: Recent advances. Progress in Polymer Science, 48, 1-39 (2015). https://doi.org/10.1016/j.progpolymsci.2014.11.002

[4] Nakajima H., Dijkstra P., Loos K.: The recent developments in biobased polymers toward general and engineering applications: Polymers that are upgraded from biodegradable polymers, analogous to petroleum-derived polymers, and newly developed. Polymers, 9, 523/1-523/26 (2017). https://doi.org/10.3390/polym9100523

[5] Zia K. M., Noreen A., Zuber M., Tabasum S., Mujahid M.: Recent developments and future prospects on biobased polyesters derived from renewable resources: A review. International Journal of Biological Macromolecules, 82, 1028-1040 (2016).

https://doi.org/10.1016/j.ijbiomac.2015.10.040

[6] Dimitriadis T., Bikiaris D. N., Papageorgiou G. Z., Floudas G.: Molecular dynamics of poly(ethylene-2,5furanoate) (PEF) as a function of the degree of crystallinity by dielectric spectroscopy and calorimetry. Macromolecular Chemistry and Physics, 217, 20562062 (2016).

https://doi.org/10.1002/macp.201600278

[7] Kucherov F. A., Gordeev E. G., Kashin A. S., Ananikov V. P.: Three-dimensional printing with biomass-derived PEF for carbon-neutral manufacturing. Angewandte Chemie, 129, 16147-16151 (2017). https://doi.org/10.1002/ange.201708528

[8] van Berkel J. G., Guigo N., Kolstad J. J., Sbirrazzuoli N.: Biaxial orientation of poly(ethylene 2,5-furandicarboxylate): An explorative study. Macromolecular Materials and Engineering, 303, 1700507/1-1700507/9 (2018).

https://doi.org/10.1002/mame.201700507

[9] Burgess S. K., Kriegel R. M., Koros W. J.: Carbon dioxide sorption and transport in amorphous poly(ethylene furanoate). Macromolecules, 48, 2184-2193 (2015). https://doi.org/10.1021/acs.macromol.5b00333

[10] Burgess S. K., Karvan O., Johnson J. R., Kriegel R. M., Koros W. J.: Oxygen sorption and transport in amorphous poly(ethylene furanoate). Polymer, 55, 47484756 (2014).

https://doi.org/10.1016/j.polymer.2014.07.041

[11] Burgess S. K., Leisen J. E., Kraftschik B. E., Mubarak C. R., Kriegel R. M., Koros W. J.: Chain mobility, thermal, and mechanical properties of poly(ethylene furanoate) compared to poly(ethylene terephthalate). Macromolecules, 47, 1383-1391 (2014).

https://doi.org/10.1021/ma5000199 
[12] Weinberger S., Haernvall K., Scaini D., Ghazaryan G., Zumstein M. T., Sander M., Pellis A., Guebitz G. M.: Enzymatic surface hydrolysis of poly(ethylene furanoate) thin films of various crystallinities. Green Chemistry, 19, 5381-5384 (2017). https://doi.org/10.1039/c7gc02905e

[13] Yang Y., Zhang Q., Cao C., Cheng L., Shi Y., Yang W., Hu Y.: Solubility and solution thermodynamics of 2,5thiophenedicarboxylic acid in (water + ethanol) binary solvent mixtures. Thermochimica Acta, 592, 52-57 (2014). https://doi.org/10.1016/j.tca.2014.08.002

[14] Polen T., Spelberg M., Bott M.: Toward biotechnological production of adipic acid and precursors from biorenewables. Journal of Biotechnology, 167, 75-84 (2013). https://doi.org/10.1016/j.jbiotec.2012.07.008

[15] Deng Y., Ma L., Mao Y.: Biological production of adipic acid from renewable substrates: Current and future methods. Biochemical Engineering Journal, 105, 16-26 (2016). https://doi.org/10.1016/j.bej.2015.08.015

[16] Guidotti G., Soccio M., Lotti N., Gazzano M., Siracusa V., Munari A.: Poly(propylene 2,5-thiophenedicarboxylate) vs. poly(propylene 2,5-furandicarboxylate): Two examples of high gas barrier bio-based polyesters. Polymers, 10, 785/1-785/14 (2018).

https://doi.org/10.3390/polym10070785

[17] Guidotti G., Gigli M., Soccio M., Lotti N., Gazzano M., Siracusa V., Munari A.: Poly(butylene 2,5-thiophenedicarboxylate): An added value to the class of high gas barrier biopolyesters. Polymers, 10, 167/1-167/14 (2018). https://doi.org/10.3390/polym10020167

[18] Guidotti G., Gigli M., Soccio M., Lotti N., Salatelli E., Gazzano M., Siracusa V., Munari A.: Tailoring poly (butylene 2,5-thiophenedicarboxylate) features by the introduction of adipic acid co-units: Biobased and biodegradable aliphatic/aromatic polyesters. Polymer, 145, 11-20 (2018).

https://doi.org/10.1016/j.polymer.2018.04.063
[19] de Jong E., Dam M. A., Sipos L., Gruter G-J. M.: Furandicarboxylic acid (FDCA), a versatile building block for a very interesting class of polyesters. in 'Biobased monomers, polymers, and materials' (eds.: Smith P. B., Gross R. A.) American Chemical Society, Washington, Vol 1105, 1-13 (2012).

https://doi.org/10.1021/bk-2012-1105.ch001

[20] Hong S., Min K-D., Nam B-U., Park O. O.: High molecular weight bio furan-based co-polyesters for food packaging applications: synthesis, characterization and solid-state polymerization. Green Chemistry, 18, 51425150 (2016).

https://doi.org/10.1039/c6gc01060a

[21] Jeong Y. G., Jo W. H., Lee S. C.: Synthesis and isodimorphic cocrystallization behavior of poly (1,4-cyclohexylenedimethylene terephthalate-co-1,4-cyclohexylenedimethylene 2,6-naphthalate) copolymers. Journal of Polymer Science Part B: Polymer Physics, 42, 177-187 (2004).

https://doi.org/10.1002/polb.10691

[22] Liu J., Yee A. F.: Enhancing plastic yielding in polyestercarbonate glasses by 1,4-cyclohexylene linkage addition. Macromolecules, 31, 7865-7870 (1998). https://doi.org/10.1021/ma980370w

[23] Wang J., Liu X., Jia Z., Sun L., Zhang Y., Zhu J.: Modification of poly(ethylene 2,5-furandicarboxylate) (PEF) with 1, 4-cyclohexanedimethanol: Influence of stereochemistry of 1,4-cyclohexylene units. Polymer, 137, 173-185 (2018). https://doi.org/10.1016/j.polymer.2018.01.021

[24] Tsai Y., Fan C-H., Hung C-Y., Tsai F-J.: Poly(ethylene terephthalate) copolymers that contain 5-tert-butylisophthalic acid and 1-3/1-4-cyclohexanedimethanol: Synthesis, characterization, and properties. Journal of Applied Polymer Science, 104, 279-285 (2007). https://doi.org/10.1002/app.25592

[25] Martuscelli E., Pedone C.: The crystal and molecular structure of furane- $\alpha, \alpha^{\prime}$-dicarboxylic acid. Acta Crystallographica Section B, 24, 175-179 (1968). https://doi.org/10.1107/S0567740868001901

[26] Cai R., Preston J., Samulski E. T.: Liquid crystalline aromatic polyesters derived from 2,5-thiophene. Macromolecules, 25, 563-568 (1992).

https://doi.org/10.1021/ma00028a012 